\title{
Risk of adverse pregnancy outcomes in women with polycystic ovary syndrome: population based cohort study

\begin{abstract}
Nathalie Roos resident in obstetrics and gynaecology ${ }^{12}$, Helle Kieler associate professor and senior consultant in obstetrics and gynaecology ${ }^{2}$, Lena Sahlin associate professor and senior researcher ${ }^{3}$, Gunvor Ekman-Ordeberg professor and senior consultant in obstetrics and gynaecology ${ }^{1}$, Henrik Falconer PhD and senior consultant in obstetrics and gynaecology ${ }^{1}$, Olof Stephansson associate professor and senior consultant in obstetrics and gynaecology ${ }^{2}$
\end{abstract}

'Department of Women's and Children's Health, Division of Obstetrics and Gynaecology, Karolinska Institutet, Karolinska University Hospital, H2:01, SE-171 76 Stockholm, Sweden; ${ }^{2}$ Department of Medicine, Solna, Clinical Epidemiology Unit, Karolinska Institutet, Stockholm, Sweden; ${ }^{3}$ Department of Women's and Children's Health, Division for Reproductive Endocrinology, Karolinska Institutet, Stockholm, Sweden

\begin{abstract}
Objective To study the risk of adverse pregnancy outcomes in women with polycystic ovary syndrome, taking into account maternal characteristics and assisted reproductive technology.

Design Population based cohort study.

Setting Singleton births registered in the Swedish medical birth register between 1995 and 2007.

Participants By linkage with the Swedish patient register, 3787 births among women with a diagnosis of polycystic ovary syndrome and 1191 336 births among women without such a diagnosis.

Main outcome measures Risk of adverse pregnancy outcomes (gestational diabetes, pre-eclampsia, preterm birth, stillbirth, neonatal death, low Apgar score ( $<7$ at five minutes), meconium aspiration, large for gestational age, macrosomia, small for gestational age), adjusted for maternal characteristics (body mass index, age), socioeconomic factors (educational level, and cohabitating with infant's father), and assisted reproductive technology.

Results Women with polycystic ovary syndrome were more often obese and more commonly used assisted reproductive technology than women without such a diagnosis (60.6\% v $34.8 \%$ and $13.7 \%$ v1.5\%). Polycystic ovary syndrome was strongly associated with pre-eclampsia (adjusted odds ratio $1.45,95 \%$ confidence interval 1.24 to 1.69 ) and very preterm birth $(2.21,1.69$ to 2.90$)$ and the risk of gestational diabetes was more than doubled (2.32, 1.88 to 2.88$)$. Infants born to mothers with polycystic ovary syndrome were more prone to be large for gestational age (1.39, 1.19 to 1.62$)$ and were at increased risk of meconium aspiration (2.02, 1.13 to 3.61$)$ and having a low Apgar score $(<7)$ at five minutes (1.41, 1.09 to 1.83$)$
\end{abstract}

Conclusions Women with polycystic ovary syndrome are at increased risk of adverse pregnancy and birth outcomes that cannot be explained by assisted reproductive technology. These women may need increased surveillance during pregnancy and parturition.

\section{Introduction}

Polycystic ovary syndrome is one of the most common endocrine disorders, affecting about $5-15 \%$ of women of reproductive age. ${ }^{1-3}$ The condition is characterised by oligo-ovulation or anovulation, biochemical or clinical hyperandrogenism, and polycystic ovaries. According to the Rotterdam consensus from 2003, the presence of two of three of these criteria fulfils a diagnosis of polycystic ovary syndrome. ${ }^{4}$ The cause of polycystic ovary syndrome is not fully understood, but evidence of a genetic component has been recognised in family and twin studies. ${ }^{5}$ Oligo-ovulation or anovulation in women with polycystic ovary syndrome is a major cause of infertility, and such women might require ovulation induction or assisted reproductive technology to become pregnant. ${ }^{6}$ Changes to lifestyle can, however, improve the metabolic and endocrine consequences of having polycystic ovary syndrome, thus possibly improving infertility caused by anovulation. $^{7}$

Evidence suggests that polycystic ovary syndrome has a negative impact on pregnancy outcomes, with an increased risk of gestational diabetes, hypertensive disease during pregnancy, and preterm birth. ${ }^{8}$ Available studies are, however, limited in size and have mainly included women undergoing assisted reproductive technology. ${ }^{8}$ Consequently the extent to which 
the risk of adverse pregnancy outcomes in women with polycystic ovary syndrome is attributed to the underlying disorder or infertility treatment is uncertain. We carried out a large nationwide cohort study of pregnant women, including pregnancies conceived spontaneously and by assisted reproductive technology to evaluate the risks of adverse pregnancy and birth outcomes in women with polycystic ovary syndrome.

\section{Methods}

From the Swedish medical birth register we created a cohort among women with singleton pregnancies giving birth between 1995 and 2007. Women with polycystic ovary syndrome are more likely to undergo assisted reproductive technology, with its higher frequency of twins and higher multiple births. Because twin and multiple pregnancies differ in fetal growth and duration of gestation and have a higher occurrence of complications during pregnancy we excluded such pregnancies from the study population.

Using the unique personal identification number assigned to each citizen at birth or immigration we linked data from the Swedish medical birth register with the Swedish patient and education registers. ${ }^{10}$ The Swedish patient register, established in 1964 (nationwide since 1987), includes information on dates of hospital admissions, discharges, and diagnoses classified according to ICD codes (international classification of diseases, 7-10th revisions). Since 2001 this registry has also included information on out-patient hospital visits. We recorded the date of the first diagnosis of polycystic ovary syndrome according to ICD codes: ICD-7, 275.20 and ICD-8, 256.90

(Stein-Leventhals syndrome); ICD-9, 256E; and ICD-10, E28.2. In the Swedish version of ICD-7 and ICD-8 the codes correspond to the formerly known Stein-Leventhals syndrome. For ICD-9 and ICD-10 the code is specified as polycystic ovary syndrome and Stein-Leventhals syndrome.

\section{Register data}

Data from the Swedish medical birth register include information on about $98 \%$ of births in Sweden, with information on the mother as well as the pregnancy, delivery, and neonatal period. Data are prospectively collected, starting at the woman's first antenatal visit. ${ }^{11}$

We classified maternal age (years) at birth into four groups: 13-24, 25-29, 30-34, and $\geq 35$. Body mass index was calculated (weight $(\mathrm{kg}) /\left(\right.$ height $\left.(\mathrm{m})^{2}\right)$ and the women categorised as lean (body mass index $\leq 19.9$ ), normal weight (20.0-24.9), overweight (25.0-29.9), or obese ( $\geq 30.0)$. Parity was classified into nulliparous or parous women. Through linkage with the education register we obtained information on the number of years of formal education completed as of 1 January 2008, categorised as 11 or fewer or 12 or more. Cigarette smoking was recorded as none, 1-9 cigarettes daily, or 10 or more cigarettes daily. The Swedish medical birth register also contains information on whether the pregnancy was conceived by assisted reproductive technology or not and information on concurrent diseases such as diabetes mellitus and essential hypertension by checkbox as well as ICD-9 and ICD-10 codes. Pre-eclampsia was defined as a blood pressure reading of $140 / 90 \mathrm{~mm} \mathrm{Hg}$ or more with proteinuria of more than $0.3 \mathrm{~g}$ over 24 hours. Gestational diabetes was, according to clinical practice, defined as plasma glucose levels of $12.2 \mathrm{mmol} / \mathrm{L}$ or more after oral glucose tolerance test ( $75 \mathrm{~g}$ glucose orally administered and plasma glucose measured after two hours) or fasting blood glucose levels of $7.0 \mathrm{mmol} / \mathrm{L}$ or more. Infants born small for gestational age were defined as having birth weights of less than 2 standard deviations below the mean for gestational age and sex of the infant. Similarly, large for gestational age was defined as a birth weight of more than 2 standard deviations above the mean for gestational age. Macrosomia was defined as a birth weight of $4500 \mathrm{~g}$ or more. Post-term pregnancy was defined as delivery at 42 weeks or more of gestation and preterm birth as delivery at less than 37 weeks of gestation, classified as moderately ( $32+0$ to $36+6$ weeks $)$ and very preterm birth $(<32$ weeks). Stillbirth was defined as intrauterine fetal death after 28 weeks of gestation. A low Apgar score was defined as less than 7 at five minutes. Neonatal death was defined as death of the infant from 0 to 27 days after birth. The presence of meconium aspiration was obtained by diagnosis at discharge.

\section{Statistical analysis}

The main outcome measures were gestational diabetes, pre-eclampsia, preterm birth, stillbirth, neonatal death, low Apgar score, meconium aspiration, large for gestational age, macrosomia, and small for gestational age. Using logistic regression we estimated the risk of adverse pregnancy outcomes in relation to polycystic ovary syndrome by crude and adjusted odds ratios with $95 \%$ confidence intervals. Data were analysed using the SAS software version 9.2. We compared women with a diagnosis of polycystic ovary syndrome with women with no such diagnosis, taking into account possible confounders, such as maternal age, body mass index, parity, years of formal education, cigarette consumption, undergoing assisted reproductive technology, and calendar year of delivery. Absolute rates were standardised for difference in characteristics between women with and without polycystic ovary syndrome. In additional analyses we tested for residual confounding for the variables maternal age, body mass index, and parity by a finer categorisation and by analysing the continuous variables in a linear or linear-quadratic model.

Assisted reproductive technology refers only to in vitro fertilisation including intracytoplasmic sperm injection and not other forms of assisted reproductive technology such as ovulation induction or insemination.

Women tend to repeat pregnancy outcomes in successive births. Among women with polycystic ovary syndrome, $74.1 \%$ delivered one infant during the study period, $23.2 \%$ two infants, and $2.7 \%$ three or more infants. The corresponding frequencies among women without polycystic ovary syndrome were $53.0 \%$, $38.1 \%$, and $8.9 \%$. Because observations are not independent in women who delivered more than once during the study period, we calculated estimates using clustered data in the generalised estimation equation method (PROC GENMOD). We used a formal interaction test in the logistic regression model to estimate the possible effect modification of assisted reproductive technology and body mass index on the association between polycystic ovary syndrome and preterm birth.

\section{Results}

A total of 1195123 singleton births between 1995 and 2007 were included in the cohort, with 3787 births among mothers with a diagnosis of polycystic ovary syndrome. Women with polycystic ovary syndrome were more likely to be nulliparous than women with no such diagnosis $(53.0 \%, \mathrm{n}=1990 \vee 43.8 \%$, $\mathrm{n}=520$ 106, $\mathrm{P}<0.001)$. Undergoing assisted reproductive technology was more common in women with polycystic ovary syndrome $(13.7 \%, \mathrm{n}=510 v 1.5 \%, \mathrm{n}=18058, \mathrm{P}<0.001)$. Women with polycystic ovary syndrome had an almost doubled prevalence of a body mass index greater than $25.0(60.6 \%$, 
$\mathrm{n}=1980$ and $34.8 \%, \mathrm{n}=348340, \mathrm{P}<0.001)$. Giving birth at advanced maternal age ( $>35$ years) was more common in women with than without polycystic ovary syndrome $(19.9 \%, \mathrm{n}=753$ and $17.6 \%, \mathrm{n}=209125, \mathrm{P}<0.001)$. Women with polycystic ovary syndrome were more likely to have hypertensive disease and diabetes mellitus than women without polycystic ovary syndrome (table $1 \Downarrow$ ).

Tables $2 \Downarrow$ and $3 \Downarrow$ present absolute rates, absolute risk differences standardised for the difference in characteristics between women with and without polycystic ovary syndrome, and crude and adjusted relative risks for adverse pregnancy and birth outcomes. In the adjusted analysis, women with a previous diagnosis of polycystic ovary syndrome had a higher risk of developing gestational diabetes than women with no such diagnosis (adjusted odds ratio 2.32, 95\% confidence interval 1.88 to 2.88 ), whereas the adjusted risk difference was $1.81 \%$. There was also a strong association between polycystic ovary syndrome and pre-eclampsia $(1.45,1.24$ to 1.69$)$ and very preterm birth $(2.21$, 1.69 to 2.90$)$. Women with polycystic ovary syndrome had an $18 \%$ higher risk of undergoing caesarean section (both emergency and elective) compared with women without polycystic ovary syndrome (table 2 ).

Infants born to mothers with a previous diagnosis of polycystic ovary syndrome were more often large for gestational age (1.39, 1.19 to 1.62 ) and were also at increased risk of meconium aspiration $(2.02,1.13$ to 3.61) and a low Apgar score at five minutes (1.41, 1.09 to 1.83$)$. The risk of neonatal death was not significantly increased $(1.58,0.81$ to 3.07 ; table 3$)$. No residual confounding for maternal age, body mass index, and parity was found in sensitivity analyses (data not shown).

In a stratified analysis the adjusted odds ratio for preterm birth ( $<37+0$ weeks) among women with polycystic ovary syndrome undergoing assisted reproductive technology was 1.08 (95\% confidence interval 0.76 to 1.53 ) and among women with polycystic ovary syndrome conceiving spontaneously was 1.58 (1.33 to 1.79$)(\mathrm{P}=0.055$ for interaction, table $4 \Downarrow)$. The interaction between body mass index and polycystic ovary syndrome and the association with preterm birth was not significant.

\section{Discussion}

In the present population based study a diagnosis of polycystic ovary syndrome was associated with increased risks of adverse pregnancy outcomes that could not be attributed to the increased use of assisted reproductive technology or maternal characteristics such as advanced age or being overweight or obese.

\section{Comparison with other studies}

In previous studies preterm birth has been correlated to assisted reproductive technology, obesity, and polycystic ovary syndrome. ${ }^{8}{ }^{12} 13$ This is in congruence with the findings of this study and furthermore we also found that the risk of preterm birth among women with polycystic ovary syndrome could not be explained by maternal characteristics such as advanced age, smoking, obesity, or use of assisted reproductive technology. There was an interaction between assisted reproductive technology and polycystic ovary syndrome for preterm birth. Since women with polycystic ovary syndrome often need assisted reproductive technology or ovulation induction to become pregnant, the risk of multiple births increases, which is associated with preterm birth. In previous reports the strongest predictor for preterm birth in women with polycystic ovary syndrome was multiple birth. ${ }^{14}$ A meta-analysis ${ }^{8}$ found a $75 \%$ increased risk of preterm birth in women with polycystic ovary syndrome, but when mean length of gestation was analysed women with polycystic ovary syndrome and controls did not differ.

We found a higher proportion of macrosomia and being large for gestational age among infants of mothers with polycystic ovary syndrome. This finding is controversial since the available studies have not established this association. ${ }^{14-16}$ It is well founded that maternal obesity is associated with increased birth weight in offspring ${ }^{17}{ }^{18}$ as well as glucose intolerance and gestational diabetes. ${ }^{19}$ Women with polycystic ovary syndrome are in general more overweight than women without the condition. The estimates in the present study were, however, adjusted for body mass index, suggesting that polycystic ovary syndrome may increase the rate of fetal growth independently. Women with polycystic ovary syndrome are, regardless of body mass index, at increased risk of developing gestational diabetes, ${ }^{80}$ supported by our finding. Infants born to mothers with polycystic ovary syndrome were more likely to have low Apgar scores at five minutes and to experience meconium aspiration. These infants may be more susceptible to fetal distress during labour. However, there was no association with stillbirth, and the increased risk for neonatal death was not statistically significant. These findings need to be confirmed in future studies.

We observed a strong association between polycystic ovary syndrome and pre-eclampsia. Some studies have supported this finding, ${ }^{8}{ }^{21}$ and others not. ${ }^{14}$ It is well stated that women undergoing assisted reproductive technology are at increased risk of hypertensive disease during pregnancy, ${ }^{22}{ }^{23}$ which has been attributed to the underlying cause of infertility. In one study $^{24}$ the risk of being born small for gestational age in the offspring of women with polycystic ovary syndrome was increased, whereas this could not be confirmed in other studies. ${ }^{14-16}$ We could not find any such correlation, suggesting that maternal polycystic ovary syndrome is not associated with growth restriction.

The increased risk of caesarean section among women with polycystic ovary syndrome we found does not correspond with the findings of other studies. In a meta-analysis, ${ }^{8}$ women with polycystic ovary syndrome showed a significantly higher rate of caesarean section (odds ratio 1.56, 95\% confidence interval 1.20 to 2.02), but in a subgroup analysis restricted to studies of higher validity no significant risk was observed $(0.92,0.54$ to 1.58). Obesity has been shown to be an independent risk factor for caesarean delivery. ${ }^{25}$ In the present study, however, obesity was accounted for in the adjusted analysis.

Women with polycystic ovary syndrome can conceive spontaneously but with a delayed fertile window since there is a tendency of regular menstrual cycles with advancing age. ${ }^{26}$ In the present study we found that women with polycystic ovary syndrome were slightly older than women without polycystic ovary syndrome. Advanced maternal age is strongly correlated with many of the adverse pregnancy outcomes in this study ${ }^{27}$; however, although we adjusted for maternal age in the multivariate analysis, a residual effect could still be possible.

\section{Strengths and limitations of the study}

A major strength of this study was the large sample size, making it possible to study rare pregnancy outcomes such as stillbirth, meconium aspiration, low Apgar scores at five minutes, and neonatal death. In this population based study we included women with pregnancies that were spontaneously conceived as well as conceived by assisted reproductive technology. Women 
with polycystic ovary syndrome according to the Rotterdam criteria, ${ }^{4}$ and not seeking medical assistance for irregular menstrual periods or infertility problems, might have been incorrectly classified as not having the disease. Such misclassification would lead to an underestimation of the association between polycystic ovary syndrome and adverse pregnancy outcomes. When the National Institutes of Health and Rotterdam criteria for polycystic ovary syndrome were compared, the prevalence was doubled. ${ }^{28} 29$ This may imply an underestimation of women with polycystic ovary syndrome at the start of the study period, when the National Institutes of Health criteria was used. However, we adjusted for calendar period in the multivariate analyses. Furthermore, it is likely that we included women with more severe disease as exposed, and the findings may consequently not be generalisable to all women with polycystic ovary syndrome.

\section{Possible pathophysiological mechanisms}

The pathophysiological mechanisms behind the increased risk of adverse pregnancy outcomes among women with polycystic ovary syndrome are not fully known. In this study, polycystic ovary syndrome was associated with being overweight and obese, with an increased risk of macrosomia and large for gestational age infants, even after adjustments for body mass index. A higher prevalence of pre-eclampsia and gestational diabetes may account for increased fetal stress leading to preterm birth, low Apgar scores at five minutes, and meconium aspiration. Women with polycystic ovary syndrome have increased levels of androgens, which have been associated with the development of pre-eclampsia. ${ }^{30}$ Metformin treatment during pregnancy does not seem to lower maternal androgen levels but has been shown to decrease severe pregnancy and post-partum complications, which may be mediated by reduced uterine artery impedance. ${ }^{31}{ }^{32}$ Our results do not support the notion that assisted reproductive technology mediates adverse pregnancy outcomes among women with polycystic ovary syndrome. This finding is supported by a Norwegian study, which reported that adverse outcomes are attributable to the factors leading to infertility rather than to factors related to reproductive technology. ${ }^{33}$

\section{Conclusions}

In conclusion, women with polycystic ovary syndrome are at increased risk of adverse pregnancy and perinatal outcomes, which could not be explained by assisted reproductive technology. These women may need increased surveillance during pregnancy and parturition. Future research would benefit from focusing on glucose control, medical treatment, and hormonal status among women with polycystic ovary syndrome during pregnancy.

Contributors: NR, HK, and OS designed the study. NR did the statistical analyses, reviewed the research, and wrote the introduction, methods, results, discussion, and conclusions. LS, GE-O, HF, HK, and OS helped write and review the methods, results, discussion, and conclusions. OS assisted in the statistical analyses. GE-O, LS, and OS are the guarantors.

Competing interests: All authors have completed the ICMJE uniform disclosure form at www.icmje.org/coi_disclosure.pdf (available on request from the corresponding author) and declare: that this study received financial support from the Swedish Research Council (projects 73X-20137 (LS) 73X-14612 (GEO)) and the board of postgraduate education at Karolinska Institutet, Stockholm, Sweden (Karolinska Institutet Doctoral Student Financing Funds (KID)) (NR) for the submitted work, and that financial support was also provided through the regional agreement on medical training and clinical research (ALF) between
Stockholm County Council and Karolinska Institutet (LS); no financial relationships with any organisations that might have an interest in the submitted work in the previous three years; and no other relationships or activities that could appear to have influenced the submitted work.

Ethical approval: This study was approved by the Karolinska Institute's local ethics committee.

Data sharing: No additional data available.

Archer JS, Chang RJ. Hirsutism and acne in polycystic ovary syndrome. Best Pract Res Clin Obstet Gynaecol 2004;18:737-54.

2 Asuncion M, Calvo RM, San Millan JL, Sancho J, Avila S, Escobar-Morreale HF. A prospective study of the prevalence of the polycystic ovary syndrome in unselected Caucasian women from Spain. J Clin Endocrinol Metab 2000;85:2434-8.

3 Knochenhauer ES, Key TJ, Kahsar-Miller M, Waggoner W, Boots LR, Azziz R. Prevalence of the polycystic ovary syndrome in unselected black and white women of the southeastern United States: a prospective study. J Clin Endocrinol Metab 1998;83:3078-82.

4 Rotterdam ESHRE/SRM-sponsored PCOS Consensus Workshop Group. Revised 2003 consensus on diagnostic criteria and long-term health risks related to polycystic ovary syndrome (PCOS). Hum Reprod 2004;19:41-7.

5 Legro RS, Driscoll D, Strauss JF 3rd, Fox J, Dunaif A. Evidence for a genetic basis for hyperandrogenemia in polycystic ovary syndrome. Proc Natl Acad Sci USA 1998:95:14956-60

6 Rajashekar L, Krishna D, Patil M. Polycystic ovaries and infertility: our experience. J Hum Reprod Sci 2008;1:65-72

7 Moran LJ, Hutchison SK, Norman RJ, Teede HJ. Lifestyle changes in women with polycystic ovary syndrome. Cochrane Database Syst Rev 2011;2:CD007506.

8 Boomsma CM, Eijkemans MJ, Hughes EG, Visser GH, Fauser BC, Macklon NS. A meta-analysis of pregnancy outcomes in women with polycystic ovary syndrome. Hum Reprod Update 2006;12:673-83.

9 Heijnen EM, Eijkemans MJ, Hughes EG, Laven JS, Macklon NS, Fauser BC. A meta-analysis of outcomes of conventional IVF in women with polycystic ovary syndrome. Hum Reprod Update 2006;12:13-21.

10 Ludvigsson JF, Otterblad-Olausson P, Pettersson BU, Ekbom A. The Swedish persona identity number: possibilities and pitfalls in healthcare and medical research. Eur $J$ Epidemiol 2009;24:659-67.

11 Cnattingius S, Ericson A, Gunnarskog J, Kallen B. A quality study of a medical birth registry. Scand J Soc Med 1990;18:143-8.

12 Schieve LA, Meikle SF, Ferre C, Peterson HB, Jeng G, Wilcox LS. Low and very low birth weight in infants conceived with use of assisted reproductive technology. N Engl J Med 2002;346:731-7.

13 Cnattingius S, Bergstrom R, Lipworth L, Kramer MS. Prepregnancy weight and the risk of adverse pregnancy outcomes. N Engl J Med 1998;338:147-52.

14 Mikola M, Hiilesmaa V, Halttunen M, Suhonen L, Tiitinen A. Obstetric outcome in women with polycystic ovarian syndrome. Hum Reprod 2001;16:226-9.

15 Haakova L, Cibula D, Rezabek K, Hill M, Fanta M, Zivny J. Pregnancy outcome in women with PCOS and in controls matched by age and weight. Hum Reprod 2003:18:1438-41.

16 Vollenhoven B, Clark S, Kovacs G, Burger H, Healy D. Prevalence of gestational diabetes mellitus in polycystic ovarian syndrome (PCOS) patients pregnant after ovulation induction with gonadotrophins. Aust NZ J Obstet Gynaecol 2000;40:54-8.

17 Baeten JM, Bukusi EA, Lambe M. Pregnancy complications and outcomes among overweight and obese nulliparous women. Am J Public Health 2001:91:436-40.

18 Surkan PJ, Hsieh CC, Johansson AL, Dickman PW, Cnattingius S. Reasons for increasing trends in large for gestational age births. Obstet Gynecol 2004;104:720-6.

19 Cok T, Tarim E, Bagis T. Isolated abnormal value during the 3-hour glucose tolerance test: which value is associated with macrosomia? $J$ Matern Fetal Neonatal Med 2011;24:1039-41.

20 Radon PA, McMahon MJ, Meyer WR. Impaired glucose tolerance in pregnant women with polycystic ovary syndrome. Obstet Gynecol 1999:94:194-7.

21 Fridstrom M, Nisell H, Sjoblom P, Hillensjo T. Are women with polycystic ovary syndrome at an increased risk of pregnancy-induced hypertension and/or preeclampsia? Hypertens Pregnancy 1999;18:73-80.

22 Kallen B, Finnstrom O, Nygren KG, Otterblad Olausson P, Wennerholm UB. In vitro fertilisation in Sweden: obstetric characteristics, maternal morbidity and mortality. BJOG 2005;112:1529-35.

23 Jackson RA, Gibson KA, Wu YW, Croughan MS. Perinatal outcomes in singletons following in vitro fertilization: a meta-analysis. Obstet Gynecol 2004;103:551-63.

24 Sir-Petermann T, Hitchsfeld C, Maliqueo M, Codner E, Echiburu B, Gazitua R, et al. Birth weight in offspring of mothers with polycystic ovarian syndrome. Hum Reprod 2005;20:2122-6.

25 Sheiner E, Levy A, Menes TS, Silverberg D, Katz M, Mazor M. Maternal obesity as an independent risk factor for caesarean delivery. Paediatr Perinat Epidemiol 2004;18:196-201.

26 Hudecova M, Holte J, Olovsson M, Sundstrom Poromaa I. Long-term follow-up of patients with polycystic ovary syndrome: reproductive outcome and ovarian reserve. Hum Reprod 2009;24:1176-83.

27 Usta IM, Nassar AH. Advanced maternal age. Part I: obstetric complications. Am J Perinatol 2008:25:521-34.

28 March WA, Moore VM, Willson KJ, Phillips DI, Norman RJ, Davies MJ. The prevalence of polycystic ovary syndrome in a community sample assessed under contrasting diagnostic criteria. Hum Reprod 2010;25:544-51.

29 Tehrani FR, Simbar M, Tohidi M, Hosseinpanah F, Azizi F. The prevalence of polycystic ovary syndrome in a community sample of Iranian population: Iranian PCOS prevalence study. Reprod Biol Endocrinol 2011:9:39.

30 Troisi R, Potischman N, Johnson CN, Roberts JM, Lykins D, Harger G, et al. Estrogen and androgen concentrations are not lower in the umbilical cord serum of pre-eclamptic pregnancies. Cancer Epidemiol Biomarkers Prev 2003;12(11 Pt 1):1268-70.

31 Salvesen KA, Vanky E, Carlsen SM. Metformin treatment in pregnant women with polycystic ovary syndrome-is reduced complication rate mediated by changes in the uteroplacental circulation? Ultrasound Obstet Gynecol 2007:29:433-7. 


\section{What is already known on this topic}

Women with polycystic ovary syndrome undergoing assisted reproductive technology have increased risks of gestational diabetes, pre-eclampsia, and preterm birth

\section{What this study adds}

Irrespective of the use of assisted reproduction, polycystic ovary syndrome is associated with preterm birth, gestational diabetes, and pre-eclampsia

Infants born to mothers with polycystic ovary syndrome are more likely to have a low Apgar score at five minutes, have meconium aspiration, and be large for gestational age

32 Vanky E, Salvesen KA, Heimstad R, Fougner KJ, Romundstad P, Carlsen SM. Metformin reduces pregnancy complications without affecting androgen levels in pregnant polycystic ovary syndrome women: results of a randomized study. Hum Reprod 2004;19:1734-40.

33 Romundstad LB, Romundstad PR, Sunde A, von During V, Skjaerven R, Gunnell D, et al. Effects of technology or maternal factors on perinatal outcome after assisted fertilisation: a population-based cohort study. Lancet 2008;372:737-43.

Accepted: 11 September 2011

\section{Cite this as: BMJ 2011:343:d6309}

This is an open-access article distributed under the terms of the Creative Commons Attribution Non-commercial License, which permits use, distribution, and reproduction in any medium, provided the original work is properly cited, the use is non commercial and is otherwise in compliance with the license. See: http://creativecommons.org/licenses/bync/2.0/ and http://creativecommons.org/licenses/by-nc/2.0/legalcode. 


\section{Tables}

Table 1| Characteristics of women with and without polycystic ovary syndrome (PCOS) giving birth to singleton pregnancies (1 195123 total births) in Sweden, 1995 to 2007

\begin{tabular}{|c|c|c|c|}
\hline \multirow[b]{2}{*}{ Maternal characteristics } & \multicolumn{2}{|c|}{ No of births (rate \%) } & \multirow[b]{2}{*}{$P$ value } \\
\hline & Women with PCOS $(n=3787)$ & Women without PCOS ( $n=1191336$ ) & \\
\hline \multicolumn{4}{|l|}{ Age (years): } \\
\hline $13-24$ & $339(8.95)$ & $188795(15.85)$ & \multirow[t]{5}{*}{$<0.001$} \\
\hline $25-29 \dagger$ & $1180(31.16)$ & $390088(32.74)$ & \\
\hline $30-34$ & $1515(40.01)$ & $403303(33.85)$ & \\
\hline$\geq 35$ & $753(19.88)$ & $209125(17.55)$ & \\
\hline Data missing & 0 & 25 & \\
\hline \multicolumn{4}{|l|}{ Body mass index: } \\
\hline$\leq 19.9$ & $148(4.53)$ & $99360(9.91)$ & \multirow[t]{5}{*}{$<0.001$} \\
\hline $20.0-24.9 \dagger$ & $1140(34.88)$ & $554456(55.33)$ & \\
\hline $25.0-29.9$ & $932(28.52)$ & $245606(24.51)$ & \\
\hline$\geq 30.0$ & $1048(32.07)$ & $102734(10.25)$ & \\
\hline Data missing & 519 & 189180 & \\
\hline \multicolumn{4}{|l|}{ Parity: } \\
\hline 0 & $1990(52.55)$ & $520106(43.66)$ & \multirow[t]{3}{*}{$<0.001$} \\
\hline$\geq 1 \dagger$ & $1797(47.45)$ & $671206(56.34)$ & \\
\hline Data missing & 0 & 24 & \\
\hline \multicolumn{4}{|l|}{ Education level (years): } \\
\hline$\leq 11$ & $2139(56.69)$ & $663449(56.11)$ & \multirow[t]{3}{*}{0.47} \\
\hline$\geq 12 \dagger$ & $1634(43.31)$ & $518974(43.89)$ & \\
\hline Data missing & 14 & 8913 & \\
\hline \multicolumn{4}{|l|}{ Cigarette consumption (daily): } \\
\hline None† & $3192(90.42)$ & $988375(88.60)$ & \multirow[t]{4}{*}{0.003} \\
\hline $1-9$ & $232(6.57)$ & $87909(7.88)$ & \\
\hline$\geq 10$ & $106(3.00)$ & 39291 (3.52) & \\
\hline Data missing & 257 & 75761 & \\
\hline \multicolumn{4}{|c|}{ Assisted reproductive technology: } \\
\hline Yes & $515(13.60)$ & $18020(1.51)$ & \multirow[t]{2}{*}{$<0.001$} \\
\hline No & $3272(86.40)$ & $1173316(98.49)$ & \\
\hline \multicolumn{4}{|l|}{ Essential hypertension: } \\
\hline Yes & $26(0.69)$ & $3345(0.28)$ & \multirow[t]{2}{*}{$<0.001$} \\
\hline No & 3761 (99.31) & 1187991 (99.72) & \\
\hline \multicolumn{4}{|l|}{ Diabetes mellitus: } \\
\hline Yes & $76(2.01)$ & $4596(0.38)$ & \multirow[t]{2}{*}{$<0.001$} \\
\hline No & 3711 (97.99) & 1186767 (99.62) & \\
\hline
\end{tabular}

*Wald test of overall effect (test of general heterogeneity).

†Reference group. 
Table 2| Pregnancy outcomes in women with and without polycystic ovary syndrome (PCOS) giving birth to singleton pregnancies (1 195 123 total births) in Sweden, 1995 to 2007

\begin{tabular}{|c|c|c|c|c|c|c|}
\hline \multirow[t]{2}{*}{ Pregnancy outcomes } & \multicolumn{2}{|c|}{ No of births (rate \%) } & \multirow{2}{*}{$\begin{array}{l}\text { Standardised } \\
\text { absolute risk } \\
\text { difference* (\%) } \\
\text { in women with } \\
\text { PCOS }\end{array}$} & \multirow{2}{*}{$\begin{array}{l}\text { Crude odds ratio } † \\
(95 \% \mathrm{Cl})\end{array}$} & \multirow{2}{*}{$\begin{array}{l}\text { Adjusted odds } \\
\text { ratiot }(95 \% \mathrm{Cl})\end{array}$} & \multirow[t]{2}{*}{$P$ value } \\
\hline & $\begin{array}{l}\text { Women with PCOS } \\
\qquad(n=3787)\end{array}$ & $\begin{array}{l}\text { Women without PCOS } \\
\qquad(n=1191336)\end{array}$ & & & & \\
\hline \multicolumn{7}{|l|}{ Gestational diabetes: } \\
\hline Yes & $125(3.30)$ & $10672(0.90)$ & 1.85 & 3.78 (3.16 to 4.52$)$ & 2.32 (1.88 to 2.88 ) & \multirow[t]{2}{*}{$<0.001$} \\
\hline No & $3662(96.70)$ & $1180664(99.10)$ & - & 1.00 & 1.00 & \\
\hline \multicolumn{7}{|l|}{ Pre-eclampsia: } \\
\hline Yes & $221(5.84)$ & 35129 (2.95) & 1.74 & 2.04 (1.78 to 2.34$)$ & 1.45 (1.24 to1.69) & \multirow[t]{2}{*}{$<0.001$} \\
\hline No & $3566(94.16)$ & 1156207 (97.05) & - & 1.00 & 1.00 & \\
\hline \multicolumn{7}{|l|}{$\begin{array}{l}\text { Antepartum bleeding or } \\
\text { placental complications: }\end{array}$} \\
\hline Yes & $59(1.56)$ & $14490(1.22)$ & - & $1.29(0.99$ to 1.66$)$ & $1.14(0.85$ to 1.53$)$ & \multirow[t]{2}{*}{0.37} \\
\hline No & $3728(98.44)$ & 1176846 (98.78) & - & 1.00 & 1.00 & \\
\hline \multicolumn{7}{|l|}{ Caesarean sectionł: } \\
\hline Yes & $846(22.44)$ & $174298(14.68)$ & 2.75 & 1.69 (1.56 to 1.82$)$ & $1.18(1.07$ to 1.29$)$ & \multirow[t]{3}{*}{0.001} \\
\hline No & $2924(77.56)$ & $1013112(85.32)$ & - & 1.00 & 1.00 & \\
\hline Data missing & 0 & 30 & - & - & - & \\
\hline \multicolumn{7}{|l|}{$\begin{array}{l}\text { Very preterm birth }(<31+6 \\
\text { weeks }) \ddagger \text { : }\end{array}$} \\
\hline Yes & $65(1.73)$ & $7999(0.67)$ & 0.94 & 2.59 (2.02 to 3.31$)$ & 2.21 (1.69 to 2.90$)$ & \multirow[t]{3}{*}{$<0.001$} \\
\hline No & $3701(98.27)$ & 1178296 (99.33) & - & 1.00 & 1.00 & \\
\hline Data missing & 4 & 1145 & - & - & - & \\
\hline \multicolumn{7}{|l|}{$\begin{array}{l}\text { Moderately preterm birth } \\
(32+0 \text { to } 36+6 \text { weeks }) \ddagger \S \text { : }\end{array}$} \\
\hline Yes & $226(6.11)$ & $50352(4.27)$ & 1.38 & 1.46 (1.28 to 1.67$)$ & $1.31(1.13$ to 1.53$)$ & \multirow[t]{3}{*}{0.0004} \\
\hline No & $3475(93.89)$ & 1127944 (95.73) & - & 1.00 & 1.00 & \\
\hline Data missing & 4 & 1145 & - & - & - & \\
\hline \multicolumn{7}{|l|}{$\begin{array}{l}\text { Post-term birth }(>42+0 \\
\text { weeks) } \neq \text { : }\end{array}$} \\
\hline Yes & $252(6.69)$ & $86771(7.31)$ & -1.39 & $0.91(0.80$ to 1.03$)$ & $0.82(0.71$ to 0.95$)$ & \multirow[t]{3}{*}{0.0069} \\
\hline No & 3514 (93.31) & 1099524 (92.69) & - & 1.00 & 1.00 & \\
\hline Data missing & 4 & 1145 & - & - & - & \\
\hline
\end{tabular}

*Estimated for significantly associated outcomes.

†Adjusted for maternal age, parity, body mass index, years of education, cigarette consumption, assisted reproductive technology, and year of delivery.

łLive births only.

§Risk compared with deliveries at 37 weeks and later. 
Table 3| Perinatal outcomes in women with and without polycystic ovary syndrome (PCOS) giving birth to singleton pregnancies (1 195 123 total births) in Sweden, 1995 to 2007

\begin{tabular}{|c|c|c|c|c|c|c|}
\hline \multirow[b]{2}{*}{ Perinatal outcomes } & \multicolumn{2}{|c|}{ No of births (rate \%) } & \multirow{2}{*}{$\begin{array}{c}\text { Standardised } \\
\text { absolute risk } \\
\text { difference (\%) } \\
\text { in women with } \\
\text { PCOS† }\end{array}$} & \multirow[b]{2}{*}{$\begin{array}{l}\text { Crude odds ratio* } \\
\qquad(95 \% \mathrm{Cl})\end{array}$} & \multirow[b]{2}{*}{$\begin{array}{l}\text { Adjusted odds ratio* } \\
\qquad(95 \% \mathrm{Cl})\end{array}$} & \multirow[b]{2}{*}{$P$ value } \\
\hline & $\begin{array}{l}\text { Women with PCOS } \\
\qquad(n=3787)\end{array}$ & $\begin{array}{l}\text { Women without } P \operatorname{COS}(n=1 \\
191336)\end{array}$ & & & & \\
\hline \multicolumn{7}{|l|}{ Stillbirth: } \\
\hline Yes & $17(0.45)$ & $3896(0.33)$ & - & 1.38 (0.85 to 2.22 ) & 0.90 (0.50 to 1.63$)$ & \multirow[t]{2}{*}{0.73} \\
\hline No & $3770(99.55)$ & $1187440(99.67)$ & - & 1.00 & 1.00 & \\
\hline \multicolumn{7}{|l|}{$\begin{array}{l}\text { Apgar score }<7 \text { at } 5 \\
\text { minutes } \neq \text { : }\end{array}$} \\
\hline Yes & $71(1.89)$ & $12909(1.10)$ & 0.54 & 1.74 (1.38 to 2.21$)$ & 1.41 (1.09 to 1.83$)$ & \multirow[t]{3}{*}{0.0095} \\
\hline No & $3680(98.11)$ & $1165776(98.90)$ & - & 1.00 & 1.00 & \\
\hline Data missing & 19 & 8755 & - & - & - & \\
\hline \multicolumn{7}{|l|}{$\begin{array}{l}\text { Neonatal death }(0-27 \\
\text { days)‡: }\end{array}$} \\
\hline Yes & $11(0.29)$ & $2179(0.18)$ & - & 1.59 (0.88-'to 2.88$)$ & $1.58(0.81$ to 3.07$)$ & \multirow[t]{2}{*}{0.18} \\
\hline No & 3759 (99.71) & 1185261 (99.82) & 一 & 1.00 & 1.00 & \\
\hline \multicolumn{7}{|l|}{ Meconium aspiration $\ddagger$ : } \\
\hline Yes & $13(0.34)$ & $1738(0.15)$ & 0.17 & 2.36 (1.37 to 4.07$)$ & 2.02 (1.13 to 3.61$)$ & \multirow[t]{2}{*}{0.018} \\
\hline No & 3757 (99.66) & $1185702(99.85)$ & - & 1.00 & 1.00 & \\
\hline \multicolumn{7}{|c|}{ Large for gestational age: } \\
\hline Yes & $238(6.32)$ & $45421(3.84)$ & 1.69 & 1.69 (1.48 to 1.93$)$ & 1.39 (1.19 to 1.62$)$ & \multirow[t]{3}{*}{$<0.001$} \\
\hline No & $3526(93.68)$ & 1138532 (96.69) & - & 1.00 & 1.00 & \\
\hline Data missing & 23 & 7383 & - & - & 一 & \\
\hline \multicolumn{7}{|c|}{$\begin{array}{l}\text { Macrosomia (birth weight } \\
\geq 4500 \mathrm{~g} \text { ): }\end{array}$} \\
\hline Yes & $194(5.14)$ & $47937(4.04)$ & - & 1.29 (1.11 to 1.49$)$ & $1.16(0.99$ to 1.36$)$ & \multirow[t]{3}{*}{0.072} \\
\hline No & $3582(94.86)$ & $1139030(95.96)$ & 一 & 1.00 & 1.00 & \\
\hline Data missing & 11 & 4369 & - & - & 一 & \\
\hline \multicolumn{7}{|c|}{ Small for gestational age: } \\
\hline Yes & $89(2.36)$ & $27192(2.30)$ & - & 1.03 (0.84 to 1.27$)$ & $1.01(0.81$ to 1.27$)$ & \multirow[t]{3}{*}{0.91} \\
\hline No & $3675(97.64)$ & $1156761(97.70)$ & - & 1.00 & 1.00 & \\
\hline Data missing & 23 & 7383 & - & - & - & \\
\hline
\end{tabular}

*Adjusted for maternal age, parity, body mass index, years of education, cigarette consumption, assisted reproductive technology, and year of delivery. †Estimated for significantly associated outcomes.

‡Live births only. 
Table 4| Adjusted odds ratios of women with and without polycystic ovary syndrome (PCOS) and singleton preterm births (<37+0 weeks) undergoing assisted reproductive technology in Sweden, 1995 to 2007

\begin{tabular}{|c|c|c|c|c|c|c|c|c|}
\hline \multirow[b]{2}{*}{ Preterm birth } & \multicolumn{2}{|c|}{ Assisted reproductive technology* } & \multirow[b]{2}{*}{ Rate } & \multirow[b]{2}{*}{$\begin{array}{l}\text { Adjusted odds } \\
\text { ratiot }(95 \% \mathrm{Cl})\end{array}$} & \multicolumn{2}{|c|}{$\begin{array}{c}\text { No assisted reproductive } \\
\text { technology }{ }^{\star}\end{array}$} & \multirow[b]{2}{*}{ Rate } & \multirow[b]{2}{*}{$\begin{array}{l}\text { Adjusted odds } \\
\text { ratio† }(95 \% \mathrm{Cl})\end{array}$} \\
\hline & Women with PCOS & $\begin{array}{l}\text { Women without } \\
\text { PCOS }\end{array}$ & & & Yes & No & & \\
\hline Yes & 41 & 1400 & 7.96 & $\begin{array}{c}1.08 \text { (0.76 to } \\
1.53)\end{array}$ & 256 & 58723 & 7.83 & $\begin{array}{c}1.54 \text { (1.33 to } \\
1.79)\end{array}$ \\
\hline No & 474 & 16618 & 7.77 & 1.00 & 3012 & 1113426 & 5.01 & 1.00 \\
\hline Data missing & 2 & - & - & - & 4 & 1167 & - & - \\
\hline
\end{tabular}

${ }^{*} \mathrm{P}=0.055$ for interaction analysis for assisted reproductive technology and PCOS in relation to preterm birth.

†Adjusted for maternal age, parity, body mass index, years of education, cigarette consumption, and assisted reproductive technology. 